\title{
Physical properties and sensory acceptance of red palm olein-based low-fat ice cream added with guar gum and xanthan gum as stabilizers
}

\author{
${ }^{1}$ Ismail, A.H., ${ }^{2}$ Wongsakul, S., ${ }^{1}$ Ismail-Fitry, M.R, ${ }^{1}$ Rozzamri, A. and ${ }^{1, *}$ Mat Yusoff, M. \\ ${ }^{1}$ Department of Food Technology, Faculty of Food Science and Technology, Universiti Putra Malaysia, \\ 43400 UPM Serdang, Selangor, Malaysia \\ ${ }^{2}$ School of Agro-Industry, Mae Fah Luang University, 333 Moo1, Thasud, Muang Chiang Rai 57100, \\ Thailand
}

\author{
Article history: \\ Received: 30 May 2020 \\ Received in revised form: 2 \\ July 2020 \\ Accepted: 16 July 2020 \\ Available Online: 4 \\ September 2020
}

\section{Keywords:}

Carotene,

Dairy,

Hydrocolloid,

Palm oil,

Vitamin A,

Vitamin E

DOI:

https://doi.org/10.26656/fr.2017.4(6).229

\begin{abstract}
Red palm olein (RPOL) is rich in nutritional and antioxidant compounds including carotenoids, tocopherols, and tocotrienols which makes it beneficial in food applications. However, to maintain the colloidal stability of RPOL in ice cream is challenging. Therefore, this study was carried out to formulate value-added ice creams supplemented with RPOL $(0.1-5.0 \% \mathrm{w} / \mathrm{w})$ in combination with guar gum $(\mathrm{GG} ; 0.0-0.4 \% \mathrm{w} / \mathrm{w})$ or xanthan gum (XG; $0.0-0.4 \% \mathrm{w} / \mathrm{w}$ ) as stabilizers. Physical properties and sensory acceptance of these ice creams were determined in comparison with selected commercial ice cream samples (CM-ice creams). Ice cream with $0.1 \%$ RPOL and $0.4 \%$ guar gum resembled CM-ice creams in terms of viscosity $(9.08 \pm 0.05$ Pa.s. $)$, hardness $(3.59 \pm 3.12$ $\mathrm{kg}$ ), and amount of melted ice cream/30 $\min (62.00 \pm 2.83 \%)$. Meanwhile, ice cream with $0.1 \%$ RPOL and $0.4 \%$ xanthan gum was similar with $\mathrm{CM}$-ice creams in their viscosity (9.19 \pm 0.04 Pa.s.) and hardness $(0.60 \pm 0.25 \mathrm{~kg})$, yet was relatively lower in the amount of melted ice cream/30 min $(33.46 \pm 5.06 \%)$. All ice creams appeared red and yellow due to the presence of RPOL, and the colour intensity was enhanced with the presence of the stabilizers. The RPOL-based ice creams displayed lower score in sensory properties than those of CM-ice creams, thus highlighted the necessary attributes that need to be improved in future studies.
\end{abstract}

\section{Introduction}

Ice cream can be discovered in various flavours, textures, and colours, and from time to time, new ice cream is developed. The fat content in ice cream helps in providing desirable flavour, forms solid texture, and maintains the added air during churning. Fat is the most solid component in ice cream which assists the ice cream to maintain its structure at room temperature even though the ice crystal begins to soften (Murray, 2007; Cree, 2017). Despite the importance of fat in an ice cream formulation, recent studies highlighted the need to decrease the fat content or replace the milk fat with plant -based oils due to unavoidable occurrence including health problems, increasing rate of obesity, suitability for lactose intolerance people, and availability of the fat and oil in a cheaper price in certain countries (O'Brien, 2009).

In light of these circumstances, Javidi et al. (2016) have formulated a low-fat dairy-based ice cream by adding stabilizers i.e. basil seed gum and guar gum. The resulted ice cream exhibited satisfactory rheological characteristics and was more favoured in creaminess as compared to full-fat ice cream. According to Panda (2010), the use of guar gum was very essential in stabilizing ice cream due to its water-binding and hydration properties. On the other hand, another common stabilizing or thickening agent in the food industry is xanthan gum which exhibits high viscosity and pseudoplastic behaviour at low shear (Dogan et al., 2012). Stabilizers, commonly polysaccharides, are frequently used to develop smooth structure and texture of ice cream, hinder or diminish the growth of both ice crystal and lactose crystal, provide stability to the ice cream, provide required reluctance to melt, and also help in enhancing the handling characteristics. Ice cream stabilizers should have a neutral flavour, plain, play a part in the meltdown of ice cream into an adequate level, produce required texture during eating, and does not unite with the ice cream flavour (Hui, 2006; NIIR Board, 2006). 
Besides replacing a certain amount of fat with stabilizers, recent studies also emphasized on replacing the milk fat with plant-based oils. Palm oil is one of the vegetable oils commonly used in producing non-dairy ice creams (Corley and Tinker, 2015), and red palm oil is one of the palm oil derivatives of interest nowadays due to its nutritional properties. As compared to other dietary fats, red palm oil is the richest source of pro-vitamin A, vitamin E, and non-vitamin A carotenoids which play important roles in preventing cancer and other chronic illnesses (Zeba et al., 2006). The compounds are natural antioxidants which can inhibit spoilage, retain the nutritional value and flavour in foods, impart important health advantages, and protect the oil from oxidative degradation (Fife, 2007). Palm oil that is high in carotene is commonly much more economical and able to be processed in various countries at an appropriate price, as compared to the artificial vitamin A. For example, red palm oil is commercialized as a beneficial source of provitamin $\mathrm{A}$ and used as a medium to fight vitamin A deficiency of people in Africa (Gunstone et al., 2007). Presence of the beneficial compounds in red palm oil makes it desirable for food applications such as confectionaries, baked goods, spreads, and margarine, among others (Lai et al., 2015; Fife, 2017). Moreover, intake of red palm oil can improve the concentration of $\alpha$ - and $\beta$-carotene in breast milk and serum of lactating and pregnant women (Lietz et al., 2001). Red palm oil can be further fractionated into red palm olein (RPOL) and red palm stearin (RPOS). Characteristics of these oils were described in details by Nagendran et al. (2000) which indicated approximate resemblance between RPOL and red palm oil, particularly in terms of their beneficial compounds.

Despite the nutritional benefits of RPOL, it is deep orange-red in colour which affects the colour of cooked foods. This situation limited the acceptability of consumers towards this oil and further leads to its underutilization. In the production of RPOL-based ice cream, too much RPOL may result in low sensory acceptability among consumers in terms of colour and taste. On the other hand, decreasing the fat content may disrupt the textural properties of the ice cream, particularly in terms of its viscosity and hardness. Therefore, this study aimed to combine the RPOL with stabilizers, i.e. guar gum or xanthan gum, and determine their relationship in the production of value-added lowfat ice cream. The use of guar gum and xanthan gum as stabilizers may assist in providing the desirable texture to the ice cream.

\section{Material and methods}

\section{$2.1 \quad$ Materials}

Ingredients used for the ice cream were purchased from Big Supermarket Sdn. Bhd. in Seri Kembangan, Selangor. RPOL was provided by Sime Darby Research Sdn. Bhd., Klang. guar gum was purchased from Meilun Food Chemical Sdn. Bhd. in Klang, while xanthan gum was purchased from Harmoni Ingredients Supply in Seri Kembangan. All these places are located in Selangor, Malaysia.

\subsection{Preparation of ice cream}

Table 1 shows the ice cream formulations used which consist of different ratios of RPOL and two different stabilizers of guar gum (later termed as GG-ice cream) and xanthan gum (later termed as XG-ice creams). The formulation was based on studies done by Arbuckle (2012) and NIIR Board (2006), while the processing method was according to Dar and Light (2014) and Goff (2003) with some modifications.

The process was initiated by pasteurizing the mixture of skim milk powder and water at $63^{\circ} \mathrm{C}$ for 30 mins, followed by homogenization of the milk for another 30 mins at the same temperature. Other ingredients were added during the homogenization step. The mixture was left overnight for ageing in a cold room at $5^{\circ} \mathrm{C}$. The aged mixture was frozen in a hard-served ice cream maker

Table 1. Formulations of ice creams with different amount of red palm olein (RPOL, 4.6-5.0\% w/w) and stabilizers (guar gum, GG; xanthan gum, XG; 0.0-0.4\% w/w)

\begin{tabular}{|c|c|c|c|c|c|c|c|c|}
\hline \multirow{2}{*}{ Ice cream } & \multicolumn{8}{|c|}{ Ingredients $(\% \mathrm{w} / \mathrm{w})$} \\
\hline & RPOL & GG & XG & MSNF & Sweetener & Emulsifier & Water & Total \\
\hline \multicolumn{9}{|c|}{ Guar gum as stabilizer } \\
\hline GG-0.0 & 5 & 0 & - & 11 & 15 & 0.3 & 68.7 & 100 \\
\hline GG-0.2 & 4.8 & 0.2 & - & 11 & 15 & 0.3 & 68.7 & 100 \\
\hline GG-0.3 & 4.7 & 0.3 & - & 11 & 15 & 0.3 & 68.7 & 100 \\
\hline GG-0.4 & 4.6 & 0.4 & - & 11 & 15 & 0.3 & 68.7 & 100 \\
\hline \multicolumn{9}{|c|}{ Xanthan gum as stabilizer } \\
\hline XG-0.0 & 5 & - & 0 & 11 & 15 & 0.3 & 68.7 & 100 \\
\hline $\mathrm{XG}-0.2$ & 4.8 & - & 0.2 & 11 & 15 & 0.3 & 68.7 & 100 \\
\hline XG-0.3 & 4.7 & - & 0.3 & 11 & 15 & 0.3 & 68.7 & 100 \\
\hline XG-0.4 & 4.6 & - & 0.4 & 11 & 15 & 0.3 & 68.7 & 100 \\
\hline
\end{tabular}


(Taylor $^{\circledR}$, Model 152-40, USA), collected in plastic packages, and were further hardened in a blast freezer at $-25^{\circ} \mathrm{C}$ for 20 mins. The ice cream samples were stored at $-18^{\circ} \mathrm{C}$ prior to analysis. Each ice cream formulation was prepared in two independent batches, and analysis methods were carried out on each batch in duplicate $(n=$ 4).

\subsection{Determination of viscosity}

The viscosity of the ice creams was determined according to Prindiville et al. (2000) by using a rheometer (HAAKE Rheostress 600, Thermo Electron Corporation, Karlsruhe, Germany). The viscosity was measured at room temperature, with shear rates of 0 to $300 \mathrm{~s}^{-1}$ at an interval of $6 \mathrm{~s}^{-1}$.

\subsection{Determination of hardness}

The hardness of the frozen ice creams was determined according to Kurt et al. (2016). A texture analyzer (TA-XT2i Texture Analyzer, Stable Micro System, Surrey, UK) with a cylindrical probe $(10 \mathrm{~mm}$ diameter) attached to a $30 \mathrm{~kg}$ load cell was used. The penetration depth of the sample was $15 \mathrm{~mm}$ at the speed of $2.0 \mathrm{~mm} \mathrm{~s}^{-1}$.

\subsection{Determination of overrun}

Overrun refers to the rise in volume after air is whipped into the liquid base of the ice cream (Cree, 2017). The percentage of overrun was calculated by using the equation proposed by Tharp and Young (2013) as follows:

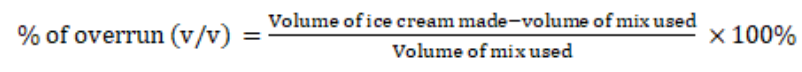

\subsection{Determination of the amount of melted ice cream}

The amount of melted ice creams was determined based on Kurt et al. (2016) with modifications. Fifty grams (i.e. the initial weight) of ice cream was allowed to melt on a $2 \mathrm{~mm}$ square opening wire mesh at room temperature. The melted ice cream was collected in a plastic cup placed under the wire mesh and was weighed after 30 mins. Later, the amount of melted ice cream was termed as "MIC30" throughout this study. The MIC30 was calculated based on the following equation:

$\%$ of melted ice cream $(\mathrm{w} / \mathrm{w})=\frac{\text { Weight of melted ice cream }(\mathrm{g})}{\text { Initial weight of ice cream }(\mathrm{g})} \times 100 \%$

\subsection{Determination of colour profile}

Colour of the ice creams was determined according to Corradini et al. (2014) by using a colorimeter (CR-410 Konica Minolta, Inc Co., Japan). The system applied was based on the International Commission on Illumination (CIE) which is an $L^{*} a^{*} b^{*}$ system.
2.8 Physical properties of commercial ice cream samples

Determination of hardness, viscosity, and MIC30 was repeated on three selected commercial scoop ice cream samples (later termed as CM-ice creams - CM1, $\mathrm{CM} 2$, and CM3) of different flavours for comparison purpose.

\subsection{Sensory evaluation}

The frozen ice creams were served to 50 untrained panellists at room temperature of approximately $25^{\circ} \mathrm{C}$. The GG- and XG-ice creams which most resembled the $\mathrm{CM}$-ice creams in terms of physical properties (hardness, viscosity, MIC30) were selected to determine the consumers' sensory acceptance in terms of colour, flavour, texture and appearance. The hedonic scale was used for each of these properties based on a scale of "1" (dislike extremely) to "9" (like extremely). Following the acceptance test was preference test which involved the selected RPOL-based ice creams and the CM-ice creams. These five samples were ranked by the panellists according to their sensory preference by using a ranking scale from 1 to 5 with $1=$ the most preferred and $5=$ the least preferred. The ranks were converted into scores according to the method of Fisher and Yates (1942) as follows: first rank: +1.03 , second rank: +0.30 , third rank: -0.30 , and fourth rank: -1.03 .

\subsection{Statistical analysis}

The final results were expressed as mean values \pm standard deviation. Statistical analysis for all results obtained was completed by using Minitab Statistical Software (Minitab Inc., State College, PA, USA) version 17 , at $95 \%$ confidence level $(\alpha=0.05)$. A two-sample t-test was carried out upon comparing two sets of data. One-way analysis of variance (ANOVA) with Tukey's multiple comparison test was used when the comparison was made between more than two sets of data.

\section{Results and discussion}

The physical properties of all ice cream samples in this study are presented in Table 2, while the images of the RPOL-based ice creams are shown in Figure 1.

\subsection{Effect of different stabilizers on the ice cream's viscosity}

Table 2 shows the ice creams' viscosities which were insignificantly different $(p>0.05)$ from each other, generally, ranging from 8.90-9.40 Pa.s.. In contrast, Marshall et al. (2003) and Kaya and Tekin (2001) stated that the viscosity of ice cream increased with the increasing amount of stabilizer and fat, among others, 
Table 1. Formulations of ice creams with different amount of red palm olein (RPOL, 4.6-5.0\% w/w) and stabilizers (guar gum, GG; xanthan gum, XG; $0.0-0.4 \% \mathrm{w} / \mathrm{w})$

\begin{tabular}{|c|c|c|c|c|c|c|c|}
\hline \multirow{2}{*}{ Ice cream } & \multicolumn{4}{|c|}{ Physical Properties } & \multicolumn{3}{|c|}{ Colour Profile } \\
\hline & Viscosity (Pa.s.) & Hardness (kg) & Overrun $(\%)$ & MIC30 (\%) & $L^{*}$ value & $a^{*}$ value & $b^{*}$ value \\
\hline \multicolumn{8}{|c|}{ Guar gum as stabilizer } \\
\hline GG-0.0 & $9.04 \pm 0.28^{b}$ & $21.84 \pm 1.72^{\mathrm{a}}$ & $8.74 \pm 3.34^{\mathrm{e}}$ & $74.51 \pm 8.61^{\mathrm{a}}$ & $65.08 \pm 2.53^{\mathrm{cd}}$ & $-0.66 \pm 1.08^{b}$ & $29.32 \pm 9.00^{\mathrm{cd}}$ \\
\hline GG-0.2 & $9.21 \pm 0.08^{\mathrm{ab}}$ & $21.46 \pm 1.54^{\mathrm{a}}$ & $13.07 \pm 2.76^{\mathrm{de}}$ & $69.11 \pm 0.92^{\mathrm{a}}$ & $61.59 \pm 2.30^{\mathrm{d}}$ & $1.79 \pm 0.40^{\mathrm{a}}$ & $34.93 \pm 1.43^{\mathrm{bc}}$ \\
\hline GG-0.3 & $9.19 \pm 0.07^{\mathrm{ab}}$ & $4.90 \pm 0.27^{\mathrm{c}}$ & $37.31 \pm 5.64^{\mathrm{ab}}$ & $62.50 \pm 15.50^{\mathrm{ab}}$ & $69.95 \pm 2.17^{\mathrm{abc}}$ & $2.35 \pm 0.09^{a}$ & $43.48 \pm 0.21^{\mathrm{a}}$ \\
\hline GG-0.4 & $9.08 \pm 0.05^{\mathrm{ab}}$ & $3.59 \pm 3.12^{\mathrm{c}}$ & $23.06 \pm 2.75^{\mathrm{cd}}$ & $62.00 \pm 2.83^{\mathrm{ab}}$ & $66.12 \pm 1.89^{\mathrm{bcd}}$ & $3.30 \pm 0.04^{\mathrm{a}}$ & $44.93 \pm 1.30^{\mathrm{a}}$ \\
\hline \multicolumn{8}{|c|}{ Xanthan gum as stabilizer } \\
\hline XG-0.0 & $9.21 \pm 0.17^{\mathrm{ab}}$ & $13.22 \pm 3.91^{\mathrm{b}}$ & $26.33 \pm 1.88^{\mathrm{bc}}$ & $66.68 \pm 7.89^{a}$ & $67.98 \pm 2.67^{\mathrm{bc}}$ & $-1.84 \pm 0.25^{b}$ & $25.83 \pm 1.27^{\mathrm{d}}$ \\
\hline $\mathrm{XG}-0.2$ & $9.40 \pm 0.06^{\mathrm{a}}$ & $4.66 \pm 3.71^{\mathrm{c}}$ & $31.52 \pm 1.54^{\mathrm{abc}}$ & $36.80 \pm 1.19^{c}$ & $71.59 \pm 2.83^{\mathrm{ab}}$ & $1.63 \pm 1.56^{\mathrm{a}}$ & $43.37 \pm 2.17^{\mathrm{ab}}$ \\
\hline $\mathrm{XG}-0.3$ & $9.29 \pm 0.09^{\mathrm{ab}}$ & $0.67 \pm 0.07^{\mathrm{c}}$ & $32.26 \pm 0.50^{\mathrm{abc}}$ & $38.31 \pm 0.30^{\mathrm{c}}$ & $74.67 \pm 3.52^{\mathrm{a}}$ & $2.36 \pm 0.80^{\mathrm{a}}$ & $45.66 \pm 1.15^{\mathrm{a}}$ \\
\hline $\mathrm{XG}-0.4$ & $9.19 \pm 0.04^{\mathrm{ab}}$ & $0.60 \pm 0.25^{\mathrm{c}}$ & $38.89 \pm 1.57^{\mathrm{a}}$ & $33.46 \pm 5.06^{\mathrm{c}}$ & $65.44 \pm 3.21^{\mathrm{bcd}}$ & $3.15 \pm 0.21^{\mathrm{a}}$ & $42.21 \pm 3.48^{\mathrm{ab}}$ \\
\hline \multicolumn{8}{|c|}{ Commercial ice cream samples } \\
\hline $\mathrm{CM} 1$ & $9.02 \pm 0.26^{\mathrm{ab}}$ & $0.26 \pm 0.07^{\mathrm{c}}$ & - & $51.22 \pm 0.26^{\mathrm{ab}}$ & - & - & - \\
\hline $\mathrm{CM} 2$ & $9.04 \pm 0.02^{\mathrm{ab}}$ & $0.20 \pm 0.02^{\mathrm{c}}$ & - & $60.82 \pm 1.73^{\mathrm{ab}}$ & - & - & - \\
\hline CM3 & $8.90 \pm 0.07^{b}$ & $0.10 \pm 0.02^{\mathrm{c}}$ & - & $60.91 \pm 2.79^{\mathrm{ab}}$ & - & - & - \\
\hline
\end{tabular}

GG, guar gum; XG, xanthan gum; CM, commercial ice cream sample; MIC30, melted amount of ice cream after 30 mins left at room temperature. Mean values \pm standard deviation followed by the same letter in each column are not significantly different ( $p$ $>0.05$ ) as determined by analysis of variance (ANOVA) and Tukey's Multiple Comparison Test

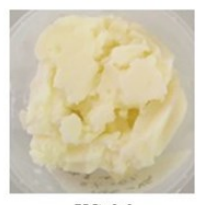

$\mathrm{XG}-0.0$

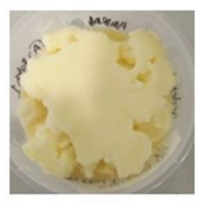

GG-0.0

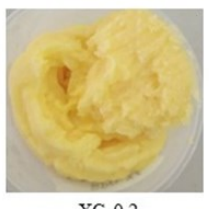

$\mathrm{XG}-0.2$

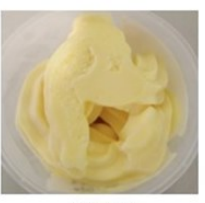

GG-0.2

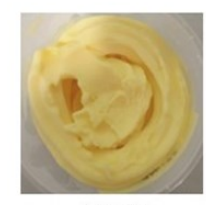

$\mathrm{XG}-0.3$

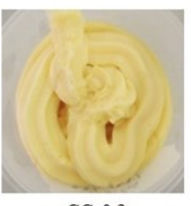

GG-0.3

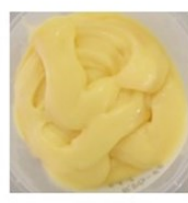

$\mathrm{XG}-0.4$

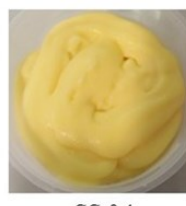

GG-0.4
Figure 1. Ice creams with different amount of red palm olein (RPOL) $(5.0,4.8,4.7,4.6 \% \mathrm{w} / \mathrm{w})$ and stabilizers $(0.0,0.2,0.3$, $0.4 \% \mathrm{w} / \mathrm{w}) . \mathrm{XG}$, xanthan gum; GG, guar gum.

with the former exhibited greater effect. Dogan et al. (2012) also stated that a stabilizer is added to increase the mix viscosity and influence the final quality of the ice cream.

According to Mudgil et al. (2011), guar gum possesses a faster ability to hydrate in cold water to form a high-viscous solution. However, in this study, the GGice cream mix was pasteurized and homogenized at $63^{\circ} \mathrm{C}$ prior to ageing and hardening was done at a lower temperature (Method 2.2). The temperature fluctuation may have changed the guar gum's structure that reduces the hydration ability. Another possibility was the competition between sugar and guar gum for hydration which subsequently decreased the guar gum's hydration capacity (Sharma et al., 2018). These conditions caused guar gum to exhibit similar performance even at the different amount and therefore resulted in ice creams with insignificantly different $(p>0.05)$ viscosity. Despite this finding, the GG-ice creams were similar ( $p$ $>0.05$ ) in viscosity with those of CM-ice creams.

On the other hand, Zhao et al. (2009) stated that xanthan gum is a dose-dependent stabilizer. Habibi and Khosravi-Darani (2017) highlighted that xanthan gum has the ability to enhance viscosity, while Liu et al. (2018) reported that xanthan gum has the stabilizing effect on the air bubbles in ice cream. Thus, a higher amount of xanthan gum should increase the viscosity of the ice cream. Insufficient xanthan gum $(0.2-0.4 \% \mathrm{w} / \mathrm{w})$ used in this study might result in insignificantly different $(p>0.05)$ ice cream viscosity. This range was predetermined based on the maximum amount of xanthan gum added into milk-based food products $(0.3-0.5 \% \mathrm{w} /$ w), in accord with the Food and Agriculture Organization (FAO). The viscosity values of XG-ice creams, however, showed no significant different $(\mathrm{p}>$ 0.05 ) from that of CM-ice creams.

All XG-ice creams recorded higher viscosities than GG- and CM-ice creams, yet the differences were insignificant $(p>0.05)$. xanthan gum exhibits thickening characteristics with pseudoplastic behaviour due to its branch structure. This characteristic enables xanthan gum to be more stable in various ranges of temperature, $\mathrm{pH}$, and upon enzyme degradation. Therefore, xanthan gum was reported to be better than guar gum, locust bean gum, and other types of natural gums, and led to viscosity enhancement (Habibi and Khosravi-Darani, 2017). However, at a lower amount of xanthan gum 
added in this research, no effect was recorded.

\subsection{Effect of different stabilizers on the ice cream's hardness}

The hardness of ice cream is affected by the amount of fat and fat replacer, the ice crystal size, overrun, fat destabilization extent, and volume of ice phase (Javidi et al., 2016; Góral et al., 2018). Ice cream with large ice crystal exhibits hard texture, while ice cream with small ice crystal exhibits a softer texture which forms a creamy ice cream (Góral et al., 2018).

With reference to Table 2, both GG-0.0 $(21.84 \pm 1.72$ $\mathrm{kg})$ and GG-0.2 $(21.46 \pm 1.54 \mathrm{~kg})$ exhibited significantly highest $(p<0.05)$ hardness in comparison to other ice creams with higher guar gum levels. It was highly probable that the use of $0.3 \%(\mathrm{w} / \mathrm{w})$ and $0.4 \%(\mathrm{w} / \mathrm{w})$ guar gum resulted in the formation of less ice crystals, mainly in small sizes, which imparted smoother textures to the ice creams (GG-0.3, GG-0.4) (Góral et al., 2018). Furthermore, it was assumed that both GG-0.3 and GG0.4 exhibited smoother texture due to the guar gum's ability at these levels to incorporate with part of the water in the ice cream mix (Arbuckle, 2012). Despite the lower hardness values, both GG-0.3 and GG-0.4 exhibited insignificantly different $(p>0.05)$ hardness with CM-ice creams. This finding indicated the ability of guar gum at $0.3 \%(\mathrm{w} / \mathrm{w})$ and $0.4 \%(\mathrm{w} / \mathrm{w})$ levels in providing the desirable hardness to the ice creams. On the other hand, increasing the amount of xanthan gum had decreased the ice cream's hardness, yet insignificantly $(p>0.05)$. This trend of decreasing in hardness upon the higher amount of stabilizer was in line with the study done by Karaca et al. (2009) which reported decreased in an ice cream's hardness upon addition of fat replacer. Habibi and Khosravi-Darani (2017) stated that the use of xanthan gum in muffins, biscuits, or cakes improved the water-binding property, provided better smoothness, and better air retention.

When GG-0.0 and XG-0.0 (of same formulations) were compared, their hardness values were significantly different $(\mathrm{p}<0.05)$. This might occur due to absence of stabilizer in both formulation which causes the ice creams to be unstable during processing and analysis. Overall, all GG- and XG-ice creams exhibited desirable hardness which were comparable with $\mathrm{CM}$-ice creams except for GG-0.0, GG-0.2, and XG-0.0.

\subsection{Effect of different stabilizers on the ice cream's overrun}

Overrun determines the air content in an ice cream which is crucial for volume increment (Liu et al., 2018). Ice creams with lower overrun incorporated smaller volume of air and tend to form larger ice crystals, thus, imparting higher hardness and non-smooth texture to the ice cream. However, this type of ice cream melts quicker (Sofjan and Hartel, 2004; Góral et al., 2018; Liu et al., 2018). This relationship was true in the case of both GG0.0 and XG- 0.0 which exhibited the lowest overrun as compared to other ice creams containing the stabilizers. Góral et al. (2018) also reported the lowest overrun for ice cream without stabilizer. Therefore, this finding proved the ability of both GG and XG in enhancing the overrun of ice cream. Nevertheless, the GG-0.0 and XG0.0 exhibited significant different $(\mathrm{p}<0.05)$ overrun despite being similar in formulations which were most likely due to the absence of stabilizer as explained in Section 3.3 for hardness.

Table 2 also shows significantly higher $(\mathrm{p}<0.05)$ overrun of XG-ice creams compared to GG-ice creams, except between GG-0.3 and XG-0.3. Xanthan gum is known to exhibit thickening characteristics. Therefore, the addition of xanthan gum increased the amount of incorporated air, thus increased the food's volume, produced uniform size of air cells with constant distribution, and prevented the air bubbles from elapsing (Nussinovitch, 1997; Allen et al., 2006). On the other hand, Liu et al. (2018) reported the lowest and highest overrun in ice creams with $10 \%(\mathrm{w} / \mathrm{w})$ and $0.1 \%(\mathrm{w} / \mathrm{w})$ fat content, respectively. Therefore, the highest overrun in XG- 0.4 can be due to its lowest fat content of $0.1 \%$ $(\mathrm{w} / \mathrm{w})$, besides the ability of $\mathrm{XG}$ itself in enhancing the overrun.

\subsection{Effect of different stabilizers on the amount of melted ice cream}

Ice cream with higher overrun indicates incorporation of higher air volume. Air acts as an excellent insulator which lowers the rate of heat transfer into the ice cream and therefore increase its melting resistance (Sofjan and Hartel, 2004). Different fat content and type of fat replacer used will cause various melting rate of an ice cream (Karaca et al., 2009).

With reference to Table 2, GG-0.0 exhibited highest (yet insignificant, $p>0.05$ ) MIC30 which was undesirable, as compared to other GG-ice creams. This finding was due to the lowest air volume incorporated in GG-0.0 as indicated by its lowest overrun (Table 2). Furthermore, Javidi et al. (2016) reported higher melting resistance in ice creams developed with the addition of stabilizers i.e. guar gum, basil seed gum, and their blend; and the melting resistance increased as the amount of these stabilizers increased. Table 2 also shows insignificantly different $(p>0.05)$ MIC30 between GGice creams and $\mathrm{CM}$-ice creams. In the case of XG-ice creams, all XG-0.2, XG-0.3, and XG-0.4 showed 
significantly lowest $(\mathrm{p}<0.05)$ MIC30 which proved the ability of xanthan gum in enhancing the melting resistance of the ice creams. Additionally, the MIC30 of XG-ice creams were significantly lower $(p<0.05)$ than those of GG-ice creams, except for GG-0.0 and XG-0.0 which were insignificantly different $(p>0.05)$ from each other. This finding proved the greater ability of xanthan gum as compared to guar gum in increasing the melting resistance of ice cream.

\subsection{Colour profile}

Table 2 shows the colour profile of the ice creams, with their images shown in Figure 1. All GG- and XGice creams exhibited fluctuating $L^{*}$ values between 60.00 -70.00 and 65.00-75.00, respectively. Significantly higher $(\mathrm{p}<0.05) L^{*}$ value in the GG-0.3 was in line with its significantly highest $(\mathrm{p}<0.05)$ overrun value. A similar correlation can be observed between the highest $L^{*}$ values and overrun of XG-0.2 and XG-0.3. Therefore, it was highly expected that colour dilution took place upon higher air volume incorporation in these ice cream samples which therefore resulted in their highest $L^{*}$ values. On the other hand, according to Hadnađev et al. (2014), the overall light scattering characteristic of fat decreased in low-fat ice cream due to its lower fat content, thus resulted in a darker colour (i.e. lower $L^{*}$ value) as compared to full-fat ice cream. This trend was not observed in this study which highly indicates the insignificant effect of the RPOL content used (1-5\% w/ w) on its overall light scattering characteristics.

Table 2 also reveals significantly lower $a^{*}$ values of GG-0.0 and XG-0.0 as compared to other GG- and XGice creams. As the stabilizer level increased, the $a^{*}$ values increased, yet insignificantly $(p>0.05)$. Both GG -0.0 and XG-0.0 also exhibited negative $a^{*}$ values which indicated greenish colour, despite having highest RPOL $(5 \% \mathrm{w} / \mathrm{w})$ content than that of other ice creams. These findings highlighted the significant effect of stabilizers (guar gum and xanthan gum), either in increasing the $a^{*}$ values and/or in decreasing the greenness of the ice creams. A similar trend was reported by Kumar and Mishra (2004), where the increased level of stabilizer causes decrease in the greenness of set yoghurt fortified with mango pulp and soymilk blend. Furthermore, in a study done by Hadnađev et al. (2014), the addition of maltodextrin as a stabilizer significantly changed the $a^{*}$ value of reduced-fat ice cream, and the value increased insignificantly upon higher maltodextrin level.

The $b^{*}$ values showed a similar trend with that of $a^{*}$ values of both GG-0.0 and XG-0.0 which were significantly lowest $(\mathrm{p}<0.05)$ as compared to other ice creams, and the values significantly increased $(p<0.05)$ upon addition of stabilizers. In other words, ice cream with lower RPOL content (i.e. contained stabilizers) were higher in both redness and yellowness. This finding further supports the ability of stabilizers in enhancing the ice cream's colour, not only the redness as explained earlier. Despite this finding, none of the ice creams was negative in $b^{*}$ value which indicated their yellowish colour due to presence of RPOL in the formulations.

\subsection{Sensory evaluation}

In accord with the physical properties, GG-0.4 recorded no significant difference $(\mathrm{p}>0.05)$ with all $\mathrm{CM}$ -ice creams in terms of viscosity, hardness, and MIC30. On the other hand, the XG-0.4 resembled the CM-ice creams in their viscosity and hardness, besides exhibiting the lowest MIC30 and highest overrun as compared to other XG-ice creams. Therefore, the following sensory acceptance and preference tests involved both of these GG-0.4 and XG-0.4.

As shown in Figure 2, XG-0.4 received higher acceptance scores as compared to GG- 0.4 for all attributes, yet the differences were insignificant $(\mathrm{p}>$ $0.05)$. This finding partly proved the claim by Habibi and Khosravi-Darani (2017) on better xanthan gum performance as compared to other natural gums due to its good thickening and stabilizing characteristics. Moreover, according to Nussinovitch (1997), the addition of $0.2 \%(\mathrm{w} / \mathrm{w})$ xanthan gum provided resistance towards heat-shock and produced better mouth-feel frozen desserts such as sherbets and ice cream. In overall, all sensory acceptance scores were higher than the middle score which indicated a higher degree of likeness for all attributes.

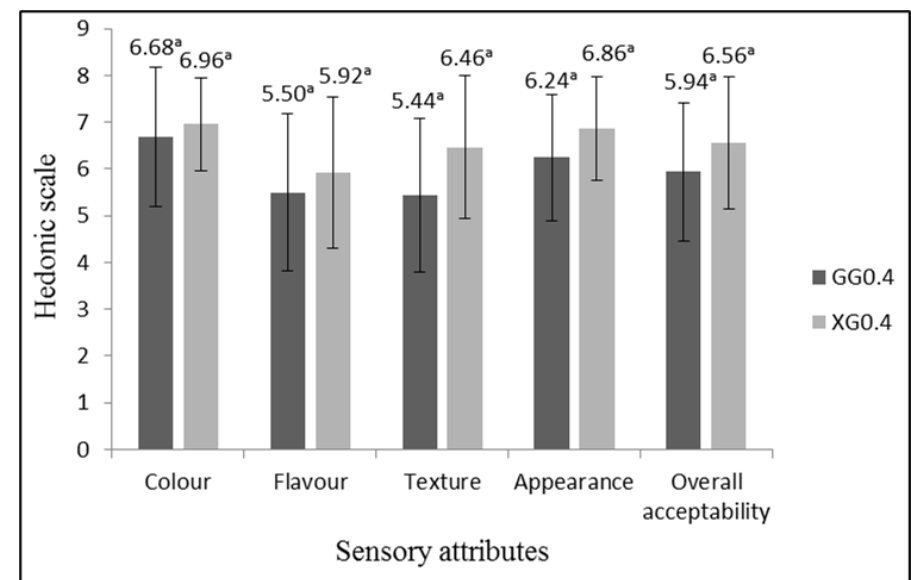

Figure 2. Sensory acceptance scores of GG-0.4 and XG-0.4 ice creams based on the hedonic scale. GG-0.4, ice cream with $4.6 \%(\mathrm{w} / \mathrm{w})$ red palm olein and $0.4 \%(\mathrm{w} / \mathrm{w})$ guar gum; $\mathrm{XG}-0.4$, ice cream with $4.6 \%(\mathrm{w} / \mathrm{w})$ red palm olein and $0.4 \%(\mathrm{w} / \mathrm{w})$ xanthan gum. Values were expressed as mean \pm standard deviation of scores obtained from 50 untrained sensory panellists. Same superscript letters on the bars denote no significant difference at $95 \%$ confidence interval

Despite this outcome, the following sensory 
preference test revealed significantly lower $(\mathrm{p}<0.05)$ consumers' preference towards RPOL-based ice creams containing both GG and XG as compared to the CM-ice creams (Figure 3). The overall perception towards an ice cream's texture was influenced by the ability of the ice cream to resist the mechanical forces contributed by the tongue, teeth, and upper palate (Aime et al., 2001; Karaca et al., 2009). Therefore, the lower preference in GG-0.4 and XG-0.4 may be related to their textural properties which greatly influenced the product's sensory quality. Both GG-0.4 and XG-0.4 exhibited harder texture (yet insignificant, $\mathrm{p}>0.05$ ), in comparison with the three CM-ice creams (Table 2). The panellists might favour the softer and creamy texture of CM-ice creams as compared to the texture of RPOL-based ice creams, and the amount of RPOL used may not be sufficient in providing the desirable creaminess towards the developed ice creams. Ice cream, ice milk, milkshakes, sherbet and water ices commonly use the combination of guar gum with xanthan gum, locust bean gum, or both as the stabilizer for higher efficiency (Sharma et al., 2006). Combination of guar gum and xanthan gum as the stabilizer may be more effective and successful in contributing better sensory properties of RPOL-based ice creams.

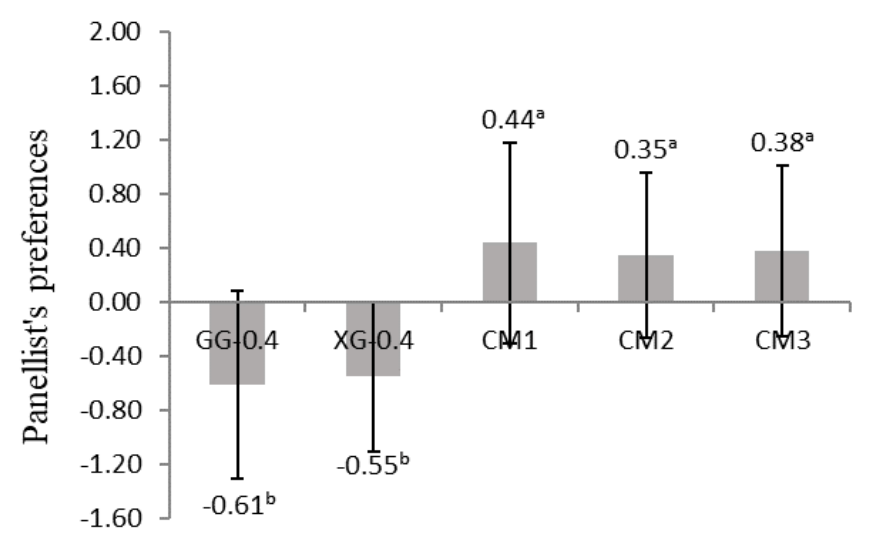

Ice cream samples

Figure 3. Sensory preferences between GG-0.4, XG-0.4, and three selected commercial ice cream samples. GG-0.4, ice cream with $4.6 \%(\mathrm{w} / \mathrm{w})$ red palm olein and $0.4 \%(\mathrm{w} / \mathrm{w})$ guar gum; XG-0.4, ice cream with $4.6 \%(\mathrm{w} / \mathrm{w})$ red palm olein and $0.4 \%(\mathrm{w} / \mathrm{w})$ xanthan gum; CM1, commercial sample 1; CM2, commercial sample 2; CM3, commercial sample 3. Values were expressed as mean \pm standard deviation of scores obtained from 50 untrained sensory panellists. Same superscript letters on the bars denote no significant difference at $95 \%$ confidence interval.

Additionally, according to Pathare et al. (2012), most food products have their unique acceptable range for colour which is influenced by many factors such as age, ethnic, consumer variability, and the surrounding during the judgement time. Colour is the most important attribute in determining sensory acceptance among consumers towards the food. The expectation for the food is to have natural colour where the consumer can detect any sign of spoilage, imperfect adulteration, or improper processing which lead to the abnormal colour of food. Clark et al. (2009) stated that the colour of lowfat ice cream or vanilla ice cream needs to be consistent, attractive, and pleasant. The addition of colouring agents in frozen dairy desserts is not compulsory as long as the colour is similar to the natural colour of beta-carotene pigment. The range of colour also cannot be too pale or too bright (Clark et al., 2009). In this study, the colour of RPOL-based ice creams was dependent on the carotenoid in the RPOL itself which acts as a natural food colourant. It was assumed that the panellists were used to the colour of the CM-ice creams but not the yellowish colour of the RPOL-based ice creams which resulted in their low degree of preference. In terms of flavour, both RPOL-based ice creams did not contain any additional flavouring agent - the sensory scores were solely dependent on the natural flavour produced from the combination of RPOL with other ingredients. Differently, the CM-ice creams contain flavouring agents which contribute to the panellists' higher degree of preference. These finding indicated the inability of RPOL to impart any favourable flavour to ice cream.

\section{Conclusion}

In overall, both guar gum and xanthan gum can potentially be added into RPOL-based ice creams to obtain the desirable physical properties, yet xanthan gum was better in decreasing the MIC30. Ice creams with added stabilizers (lower RPOL content) exhibited greater redness and yellowness intensity than those without stabilizers (highest RPOL content). These findings highlighted the significant effect of stabilizers on the colour properties of RPOL-based ice creams. Both GG0.4 and XG- 0.4 resembled CM-ice creams most in terms of physical properties, yet were significantly least $(\mathrm{p}<$ 0.05 ) preferred in their sensory properties. Therefore, the RPOL-based ice cream formulation containing guar gum and xanthan gum as stabilizers should be improved in the future, so this value-added ice cream receives greater sensory acceptance among consumers. Combination of both guar gum and xanthan gum at different ratios should also be explored.

\section{Conflict of interest}

Authors declare no conflict of interest.

\section{Acknowledgement}

The authors specially thank Sime Darby Research Sdn. Bhd. in Klang, Selangor, for providing the red palm olein. 


\section{References}

Aime, D.B., Arntfield, S.D., Malcolmson, L.J. and Ryland, D. (2001). Textural analysis of fat reduced vanilla ice cream products. Food Research International, 34(2-3), 237-246. https:// doi.org/10.1016/S0963-9969(00)00160-5

Allen, K.E., Dickinson, E. and Murray, B. (2006). Acidified sodium caseinate emulsion foams containing liquid fat: A comparison with whipped cream. LWT-Food Science and Technology, 39(3), 225-234. https://doi.org/10.1016/j.lwt.2005.02.004

Arbuckle, W. (2012). Ice Cream. $4^{\text {th }}$ ed. New York: Springer.

Clark, S., Costello, M., Drake, M. and Bodyfelt, F. (2009). The sensory evaluation of dairy products. New York: Springer Science and Business Media. https://doi.org/10.1007/978-0-387-77408-4

Corley, R. and Tinker, P. (2015). The Oil Palm. $5^{\text {th }}$ ed. Malden: Wiley-Blackwell. doi.org/10.1002/9781118953297

Corradini, S.A.S., Madrona, G.S., Visentainer, J.V., Bonafe, E.G., Carvalho, C.B., Roche, P.M. and Prado, I.N. (2014). Sensorial and fatty acid profile of ice cream manufactured with milk of crossbred cows fed palm oil and coconut fat. Journal of Dairy Science, 97(11), 6745-6753. https://doi.org/10.3168/ jds.2014-8290

Cree, D. (2017). Hello, My Name is Ice Cream: The Art and Science of the Scoop. New York: Random House USA Inc.

Dar, Y. and Light, J. (2014). Food Texture Design and Optimization. Hoboken: Wiley. https:// doi.org/10.1002/9781118765616

Dogan, M., Kayacier, A., Toker, Ö.S., Yilmaz, M.T. and Karaman, S. (2013). Steady, dynamic, creep, and recovery analysis of ice cream mixes added with different concentrations of xanthan gum. Food and Bioprocess Technology, 6(6), 1420-1433. https:// doi.org/10.1007/s11947-012-0872-z

Fife, B. (2007). The Palm Oil Miracle. Colorado: Piccadilly Books.

Fife, B. (2017). The Shocking Truth about Palm Oil. Colorado: Piccadilly Books.

Fisher, R.A. and Yates, F. (1942). Statistical Tables. London, UK: Oliver and Boyd, Ltd.

Goff, H. (2003). Ice Cream Manufacture. Food Science. Retrieved on May 15, 2020 from University of Guelph Website: https://www.uoguelph.ca/ foodscience/book-page/ice-cream-manufacture.

Góral, M., Kozłowicz, K., Pankiewicz, U., Góral, D., Kluza, F. and Wójtowicz, A. (2018). Impact of stabilizers on the freezing process, and physicochemical and organoleptic properties of coconut milk-based ice cream. LWT, 92, 516-522. https://doi.org/10.1016/j.1wt.2018.03.010

Gunstone, F., Harwood, J. and Dijkstra, A. (2007). The Lipid Handbook. $3^{\text {rd }}$ ed. Boca Raton: CRC Press. https://doi.org/10.1201/9781420009675

Habibi, H. and Khosravi-Darani, K. (2017). Effective variables on production and structure of xanthan gum and its food applications: A review. Biocatalysis and Agricultural Biotechnology, 10, 130-140. https://doi.org/10.1016/ j.bcab.2017.02.013

Hadnađev, M., Hadnađev, T.D., Dokić, L., Pajin, B., Torbica, A., Šarić, L. and Ikonić, P. (2014). Physical and sensory aspects of maltodextrin gel addition used as fat replacers in confectionery filling systems. LWT-Food Science and Technology, 59(1), 495-503. https://doi.org/10.1016/j.lwt.2014.04.044

Hui, Y. (2006). Handbook of Food Science, Technology, and Engineering. Boca Raton: Taylor and Francis.

Javidi, F., Razavi, S.M., Behrouzian, F. and Alghooneh, A. (2016). The influence of basil seed gum, guar gum and their blend on the rheological, physical and sensory properties of low fat ice cream. Food Hydrocolloids, 52, 625-633. https://doi.org/10.1016/ j.foodhyd.2015.08.006

Karaca, O.B., Güven, M., Yasar, K., Kaya, S. and Kahyaoglu, T. (2009). The functional, rheological and sensory characteristics of ice creams with various fat replacers. International Journal of Dairy Technology, 62(1), 93-99. https://doi.org/10.1111/ j.1471-0307.2008.00456.x

Kaya, S. and Tekin, A.R. (2001). The effect of salep content on the rheological characteristics of a typical ice-cream mix. Journal of Food Engineering, 47(1), 59-62. https://doi.org/10.1016/S0260-8774(00)00093 $-5$

Kumar, P. and Mishra, H.N. (2004). Mango soy fortified set yoghurt: effect of stabilizer addition on physicochemical, sensory and textural properties. Food Chemistry, 87(4), 501-507. https:// doi.org/10.1016/j.foodchem.2003.12.022

Kurt, A., Cengiz, A. and Kahyaoglu, T. (2016). The effect of gum tragacanth on the rheological properties of salep based ice cream mix. Carbohydrate Polymers, 143, 116-123. https:// doi.org/10.1016/j.carbpol.2016.02.018

Lai, O.M., Tan, C.P. and Akoh, C.C. (2015). Palm Oil: Production, Processing, Characterization, and Uses. Urbana: AOCS Press.

Lietz, G., Henry, C.J.K., Mulokozi, G., Mugyabuso, J.K., 
Ballart, A., Ndossi, G.D., Lorri, W. and Tomkins, A. (2001). Comparison of the effects of supplemental red palm oil and sunflower oil on maternal vitamin A status. The American Journal of Clinical Nutrition, 74(4), 501-509. https://doi.org/10.1093/ ajcn/74.4.501

Liu, R., Wang, L., Liu, Y., Wu, T. and Zhang, M. (2018). Fabricating soy protein hydrolysate/xanthan gum as fat replacer in ice cream by combined enzymatic and heat-shearing treatment. Food Hydrocolloids, 81, 39-47. https://doi.org/10.1016/ j.foodhyd.2018.01.031

Marshall, R., Goff, H. and Hartel, R. (2003). Ice Cream. $6^{\text {th }}$ ed. New York: Springer. https:// doi.org/10.1007/978-1-4615-0163-3

Mudgil, D., Barak, S. and Khatkar, B.S. (2014). Guar gum: processing, properties and food applicationsa review. Journal of Food Science and Technology, 51(3), 409-418. https://doi.org/10.1007/ s13197-011-0522-x

Murray, J. (2007). Milk to Ice Cream. Edina: ABDO Pub. Co.

Nagendran, B., Unnithan, U.R., Choo, Y.M. and Sundram, K. (2000). Characteristics of red palm oil, a carotene-and vitamin E-rich refined oil for food uses. Food and Nutrition Bulletin, 21(2), 189-194. https://doi.org/10.1177/156482650002100213

NIIR Board (2006). The Complete Technology Book on Flavoured Ice Cream. New Delhi: Asia Pacific Business Press, Inc.

Nussinovitch, A. (1997). Hydrocolloid Applications. London: Blackie. https://doi.org/10.1007/978-1-4615 $-6385-3$

O'Brien, R.D. (2009). Fats and Oils: Formulating and Processing for Applications. $3^{\text {rd }}$ ed. Boca Raton: CRC Press.

Panda, H. (2010). Gums and Stabilizers for Food Industry. New Delhi: Asia Pacific Business Press Inc.

Pathare, P.B., Opara, U.L. and Al-Said, F.A.J. (2013). Colour measurement and analysis in fresh and processed foods: a review. Food and Bioprocess Technology, 6(1), 36-60. https://doi.org/10.1007/ s11947-012-0867-9

Prindiville, E.A., Marshall, R.T. and Heymann, H. (2000). Effect of milk fat, cocoa butter, and whey protein fat replacers on the sensory properties of lowfat and nonfat chocolate ice cream. Journal of Dairy Science, 83(10), 2216-2223. https:// doi.org/10.3168/jds.S0022-0302(00)75105-8

Sharma, B.R., Naresh, L., Dhuldhoya, N.C., Merchant, S.U. and Merchant, U.C. (2006). Xanthan gum-A boon to food industry. Food Promotion Chronicle, 1 (5), 27-30.

Sharma, G., Sharma, S., Kumar, A., Ala'a, H., Naushad, M., Ghfar, A.A., Mola, G.T. and Stadler, F.J. (2018). Guar gum and its composites as potential materials for diverse applications: A review. Carbohydrate Polymers, 199, 534-545. https://doi.org/10.1016/ j.carbpol.2018.07.053

Sofjan, R.P. and Hartel, R.W. (2004). Effects of overrun on structural and physical characteristics of ice cream. International Dairy Journal, 14(3), 255-262. https://doi.org/10.1016/j.idairyj.2003.08.005

Tharp, B. and Young, L. (2013). Tharp and Young on Ice Cream. Lancaster, UK: DEStech Publications.

Zeba, A.N., Prével, Y.M., Somé, I.T. and Delisle, H.F. (2006). The positive impact of red palm oil in school meals on vitamin A status: study in Burkina Faso. Nutrition Journal, 5(1), 17. https:// doi.org/10.1186/1475-2891-5-17

Zhao, Q., Zhao, M., Yang, B. and Cui, C. (2009). Effect of xanthan gum on the physical properties and textural characteristics of whipped cream. Food Chemistry, 116(3), 624-628. https://doi.org/10.1016/ j.foodchem.2009.02.079 